Original Research Paper

\title{
Correlation of Oxytocin (OTR) and Estrogen Receptor (ER) mRNA in the Canine Placenta with the Detected Circulating Levels of Oxytocin and Estrogen during Pregnancy and Parturition
}

\author{
${ }^{1}$ Gisele Almeida Lima Veiga, ${ }^{2}$ Marcella Pecora Milazzotto, ${ }^{1}$ Marcilio Nichi, \\ ${ }^{1}$ Cristina Fátima Lúcio, ${ }^{1}$ Liege Cristina Garcia Silva and ${ }^{1}$ Camila Infantosi Vannucchi \\ ${ }^{1}$ Department of Animal Reproduction, \\ School of Veterinary Medicine and Animal Science, University of São Paulo (USP), São Paulo, Brazil \\ ${ }^{2} A B C$ Federal University (UFABC), Santo André, Brazil
}

Article history

Received: 20-08-2015

Revised: $30-12-2015$

Accepted: 31-12-2015

\section{Corresponding Author:} Camila Infantosi Vannucchi Department of Animal Reproduction, School of Veterinary Medicine and Animal Science, University of São Paulo (USP), Rua Prof. Orlando Marques de Paiva, 87, São Paulo, 05508-270, Brazil $\mathrm{Ph}:+551130911423$

Email: cacavann@usp.br

\begin{abstract}
Placenta is considered an important endocrine organ during gestation, as well as can also serve as a target organ for sex steroids and pituitary hormones, mainly for the cascade of events that trigger parturition. In order to initiate studies on the canine placental endocrinology regarding estrogen and oxytocin, the present study verified the correlation among the Estrogen Receptor alpha $(\mathrm{ER} \alpha)$ and Oxytocin Receptor (OTR) gene expression in the placenta tissue with the serum concentrations of their respective hormones (estrogen and oxytocin) during canine pregnancy and parturition. Real-time PCR was performed to quantify the levels of ER $\alpha$ mRNA and OTR mRNA in the placenta tissue of bitches $(n=46)$ during Early (up to 20 days of gestation; $n=11$ ), Mid (20 to 40 days; $n=12$ ) and Late Pregnancy (40 to 60 days; $n=12$ ) and Parturition (first stage of labor; $\mathrm{n}=11$ ). Serum samples were collected for the evaluation of estradiol and oxytocin (OT) concentrations by radioimmunoassay. Placental ER $\alpha$ mRNA expression showed a progressive decrease along gestation towards parturition. Placental ER $\alpha$ mRNA expression was significantly higher until 40 days of pregnancy in comparison to Parturition. Regarding OTR mRNA expression, no statistical differences among groups were verified. The Parturition Group presented higher estrogen concentrations in relation to Early and Mid Pregnancy Groups. Serum oxytocin concentrations were not different among pregnancy and parturition. During late pregnancy, a positive correlation was observed between placental ER $\alpha$ mRNA and oxytocin serum concentration. In conclusion, ER $\alpha$ mRNA in the canine placental tissue varies in a time-dependent manner, especially during the period of placentation and placental growth. Conversely, serum estrogen concentrations do not regulate directly the changes in OT receptors expression in the canine placenta.
\end{abstract}

Keywords: Estrogen, Oxytocin, Receptor, Placenta, Canine

\section{Introduction}

Placenta is considered an important endocrine organ during gestation, as it plays a role in pregnancy maintenance, as well as in the initiation of the cascade of events that trigger parturition. However, the canine placenta has a unique characteristic, as it lacks steroidogenesis to support pregnancy, leaving to the corpus luteum the main function to produce progesterone and estrogen (Hoffmann et al., 1994; Concannon, 2009). In fact, Nishiyama et al. (1999) could not identify immunohistochemically the enzyme aromatase (estrogen convertase) and other steroidogenic enzymes in the canine placenta. Hence, circulating estrogen in pregnant dogs is apparently derived from the ovaries and is less dependent on the placenta. On the other hand, the canine 
placenta is not totally deprived of hormone synthesis, for it is the major source of relaxin, which has an autocrine and paracrine role, evidenced by the presence of relaxin receptors (Klonisch et al., 1999; Tamada et al., 2010). Thus, the canine placenta can also serve as a target organ for sex steroids and pituitary hormones, i.e., its responsiveness depends on the availability of hormone receptors. It is not possible to rule out a hormonal influence from the ovaries on placental morphological and physiological modifications during pregnancy in dogs, especially during the initial phases of gestation. Until now, the mechanism that triggers such changes in dogs is unknown, as longitudinal studies along the periods of pregnancy and parturition are scarce. In previous works, we have observed that both endometrial ER $\alpha$ mRNA and OTR mRNA remained unchanged until late pregnancy, but the expression of OTR mRNA in canine uterine tissues (endometrium and myometrium) varied over time (Veiga et al., 2015). Additionally, we have shown that the canine CL does not express ER $\alpha$ mRNA during pregnancy, whereas a decreased profile of OTR mRNA expression occurs (Veiga et al., 2014).

Regarding the physiology of gestation and labor, the canine placenta is responsible for the increasing production of prostaglandins (PGF2alpha and PGE2) along gestation (Kowalewski et al., 2010). Moreover, the prepartum release of placental prostaglandin F2alpha is the main event responsible for canine luteolysis (Concannon, 2009). Nevertheless, it has been addressed in several species that a narrow relationship exists between estrogen (E), oxytocin (OT) and prostaglandins concentrations, especially towards the transition from pregnancy to parturition. In general, the concentration of uterine oxytocin receptors increases dramatically during gestation, under the influence of the rising estrogen levels (Larcher et al., 1995). Near term, oxytocin binds to its receptors in the decidua stimulating prostaglandin synthesis (Fuchs et al., 1983). In dogs, Gram et al. (2014) reported that OTR is involved in the prepartum release of prostaglandins, as a significant increase in the expression of OTR was observed at prepartum luteolysis. However, until now, the participation of the placenta, especially regarding the relationship among $\mathrm{E}$ and OT towards uterine preparation to whelping, is uncertain.

Studies in humans have demonstrated that the concentration of OT remains low during pregnancy (Mitchell et al., 1998). Also, Klarenbeek et al. (2007) showed in dogs that plasma oxytocin concentrations remain low in late pregnancy, increasing during the expulsive stage of parturition. Therefore, it has been proposed that local OT concentrations (uterine or placental) initiates labor as a result of increased placental OT receptor (OTR) mRNA (Mitchell et al., 1998; Chibbar et al., 1993). Therefore, the increase in OTR mRNA and OT in the placenta near the end of pregnancy, combined with the anatomical proximity of the target tissues (endometrium and myometrium), support the hypothesis in women that an intra-uterine paracrine system regulates delivery (Mitchell et al., 1998). In rats, OTR levels remain low in the placenta, indicating that OTRs are regulated independently in the myometrium and the decidua (Chan et al., 1993). However, in dogs, the relationship among the circulating concentrations of $\mathrm{E}$ and $\mathrm{OT}$ and the expression of placental Estrogen Receptor (ER) and OTR has not been established, generating incomprehensive events of the canine reproductive physiology.

Hence, our purpose in the present study was to verify the correlation among the ER alpha and OTR gene expression in the placenta with the serum concentrations of their respective hormones (E and OT) during pregnancy and parturition in dogs.

\section{Materials and Methods}

\section{Animals and Experimental Groups}

The use of animals in the present study was approved by the Ethical Committee of the School of Veterinary Medicine and Animal Science-University of São Paulo.

Pregnant mongrel bitches $(n=46)$, aged 2 to 6 years, were assigned to four groups according to gestational age as established by ultrasound, reproductive history and measure of the fetal crown-rump length (Evans and Sack, 1973): Up to 20 days of gestation (Early Pregnancy Group, $n=11$ ), 20 to 40 days of gestation (Mid Pregnancy Group, $n=12$ ), 40 to 60 days of gestation (Late Pregnancy Group, $n=12$ ) and first stage of labor (Parturition Group, $\mathrm{n}=11$ ). Females of Early, Mid and Late Pregnancy Groups were subjected to ovariohysterectomy and bitches in Parturition Group underwent cesarean section followed by ovariohysterectomy.

Placental fragments (taken always from the central area of the placental girdle) were harvested during hysterotomy and, afterwards, maintained frozen at $-196^{\circ} \mathrm{C}$ until processing.

Blood samples were taken by venipuncture (left or right jugular vein) during surgery, after food had been withheld from the bitches for $12 \mathrm{~h}$. The blood samples were allowed to clot at room temperature into the evacuated tubes without anticoagulant and centrifuged for $10 \mathrm{~min}$ at $1500 \times \mathrm{g}$. The serum was drawn off, separated in 2 aliquots and stored at $-20^{\circ} \mathrm{C}$ until analysis.

\section{Real-Time PCR Amplification}

The TRIzol (Guanidinium thiocyanate-phenolchloroform extraction; Invitrogen ${ }^{\circledR}$, Carlsbad, USA) reagent was utilized for total RNA extraction from placenta tissue samples.

Total RNA was quantified after dilution in (RNasefree) water at a ratio of 1:100 in an Eppendorf® (model Vi 1.35) photometer. Subsequently, $1 \mu \mathrm{g}$ of total RNA 
was used to synthesize the first strand of cDNA by reverse transcription using the Super Script ${ }^{\circledR}$ II reverse transcriptase (Invitrogen ${ }^{\circledR}$, Carlsbad, USA) system in the presence of oligo $(\mathrm{dT})$. The obtained cDNA was stored at $-20^{\circ} \mathrm{C}$.

To quantify their levels of genetic expression, comparative analysis of the target genes (ER $\alpha$ and OTR) and endogenous controls (18S and RPS5) was performed. The cDNAs were subjected to amplification of constitutive genes $18 \mathrm{~S}$ and RPS5 as well as ER $\alpha$ and OTR with primers designed from sequences previously deposited in GenBank (www.ncbi.nml.nih.gov). In order to avoid false positive results, primers were constructed with the intron region of the amplicon.

The primer sequences were as follows: 18S, 5'TGGTTGATCCTGCCAGTAGCA-3' and 5'ATGAGCCATTCGCAGTTTCACT-3'; RPS5, 5'TCACTGGTGARACCCCCT-3' and 5'CCTGATTCACACGGCGTAG-3'; ER $\alpha$, 5'GGTCTTGGTGTTGGGTGTG-3' and 5'GGACATATTCCTCACGCTCC-3'; OTR, 5'GAACTTGTACAGCGCTTCCTC-3' and 5'GACAAAGGTGGATGAGTTGCTC-3'.

Real-time PCR was performed in an Eppendorf ${ }^{\circledR}$ Mastercycler Realplex using the Platinum ${ }^{\circledR}$ SYBR Green PCR Master Mixkit (Invitrogen ${ }^{\circledR}$, Carlsbad, USA). Sample tubes without placenta tissue were used for negative controls. No positive controls were adopted, however primers were previously standardized and simultaneously employed for amplification in other canine tissue samples (endometrium, myometrium and corpus luteum), which revealed positive amplifications (Veiga et al., $2014 ; 2015)$. All reactions were performed in a total volume of $25 \mu \mathrm{L}$ and heated to $50^{\circ} \mathrm{C}$ for $2 \mathrm{~min}$ and then $95^{\circ} \mathrm{C}$ for $10 \mathrm{~min}$ followed by 45 cycles comprising denaturation at $95^{\circ} \mathrm{C}$ for $15 \mathrm{sec}$ and then annealing for $60 \mathrm{sec}$ at the following temperatures: $61^{\circ} \mathrm{C}$ for RPS5, $60^{\circ} \mathrm{C}$ for $18 \mathrm{~S}$ and $59^{\circ} \mathrm{C}$ for $\mathrm{ER} \alpha$ and OTR. All reactions were performed as duplicates.

To calculate the relative expression levels of the target genes, Pfaffl's formula was applied to randomization tests utilizing the Relative Expression Software Tool (Rest-384C) -version 2; Munich, Germany), following the software's instructions provided by (Pfaffl et al., 2002). The efficiency of the amplification reactions for the different genes was established by amplifying serial dilutions of each sample. The relative efficiency (target gene/endogenous gene) was calculated from the slopes of product formation curves, where efficiency $=10^{-}$ 1/slope. The relative amplification efficiencies for the analyzed genes were 1.98 (18S), 2.05 (RPS5), 2.08 $(\mathrm{ER} \alpha)$ and $1.94(\mathrm{OTR})$.

\section{Hormonal Assay}

Serum estradiol concentrations were measured by radioimmunoassay with ${ }^{125} \mathrm{I}$ labeled using the commercial kit DSL-4400 (Diagnostic Systems Laboratories, Webster, Texas, USA), previously validated for canine samples. The sensitivity of the estradiol assay at $95 \%$ binding was $1.85 \mathrm{pg} \mathrm{mL}^{-1}$ and the low and high intra-assay coefficients of variation were 7.32 and $0.05 \%$, respectively.

The oxytocin assay was based on the protocol proposed by Elias et al. (1997) in which $1 \mathrm{~mL}$ of canine serum was added to acetone and ether petroleum. The oxytocin concentrations were measured through radioimmunoassay with a sensitivity of $0.9 \mathrm{pg} \mathrm{mL}^{-1}$ and the low and high intra-assay coefficients of variation were 12.6 and $7.0 \%$, respectively.

\section{Statistical Analysis}

All data were evaluated using SAS System for Windows (SAS Institute Inc., Cary, NC, USA). All variables were normally distribute and presented homogeneous variances. Therefore, the effect of gestational period was determined using parametric tests (One Way Anova-PROC GLM; LSD as post-hoc test). Pearson correlation was used to calculate the relationship between variables studied in each group.

A probability value of $\mathrm{p}<0.05$ was considered statistically significant. Results are reported as untransformed means and standard error of the mean (SEM).

\section{Results}

\section{Placenta Tissue ER $\mathrm{mRNA}$ and OTR $m R N A$}

Placenta tissue ER $\alpha$ mRNA expression showed a progressive decrease along gestation towards parturition. The expression of ER $\alpha$ mRNA was significantly $(\mathrm{p}<0.05)$ higher until 40 days of pregnancy (Early and Mid Pregnancy) in comparison to Parturition (Fig. 1). Regarding OTR mRNA expression, no statistical differences $(p>0.05)$ among groups were verified throughout pregnancy and parturition.

\section{Estrogen and Oxytocin Assay}

Parturition Group $\left(2.14 \pm 0.05 \mathrm{pg} \mathrm{mL}^{-1}\right)$ presented higher $(p<0.05)$ estrogen concentrations in relation to Early $\left(1.94 \pm 0.03 \mathrm{pg} \mathrm{mL} \mathrm{mL}^{-1}\right)$ and $\mathrm{Mid}\left(1.99 \pm 0.02 \mathrm{pg} \mathrm{mL}^{-1}\right)$ Pregnancy groups (Fig. 2). However, no statistical differences $(p>0.05)$ were verified among groups until 40 days of pregnancy, as well as between the Late Pregnancy Group (2.0 $\left.\pm 0.03 \mathrm{pg} \mathrm{mL}^{-1}\right)$ and Parturition Group.

Serum oxytocin concentrations were not different ( $>0.05$ ) among pregnancy (18.13 $\pm 4.6,20.95 \pm 9.35$, $15.29 \pm 5.93 \mathrm{pg} \mathrm{mL}^{-1}$, respectively) groups and during parturition (10.35 $\pm 5.79 \mathrm{pg} \mathrm{mL}^{-1}$ ) (Fig. 2). 


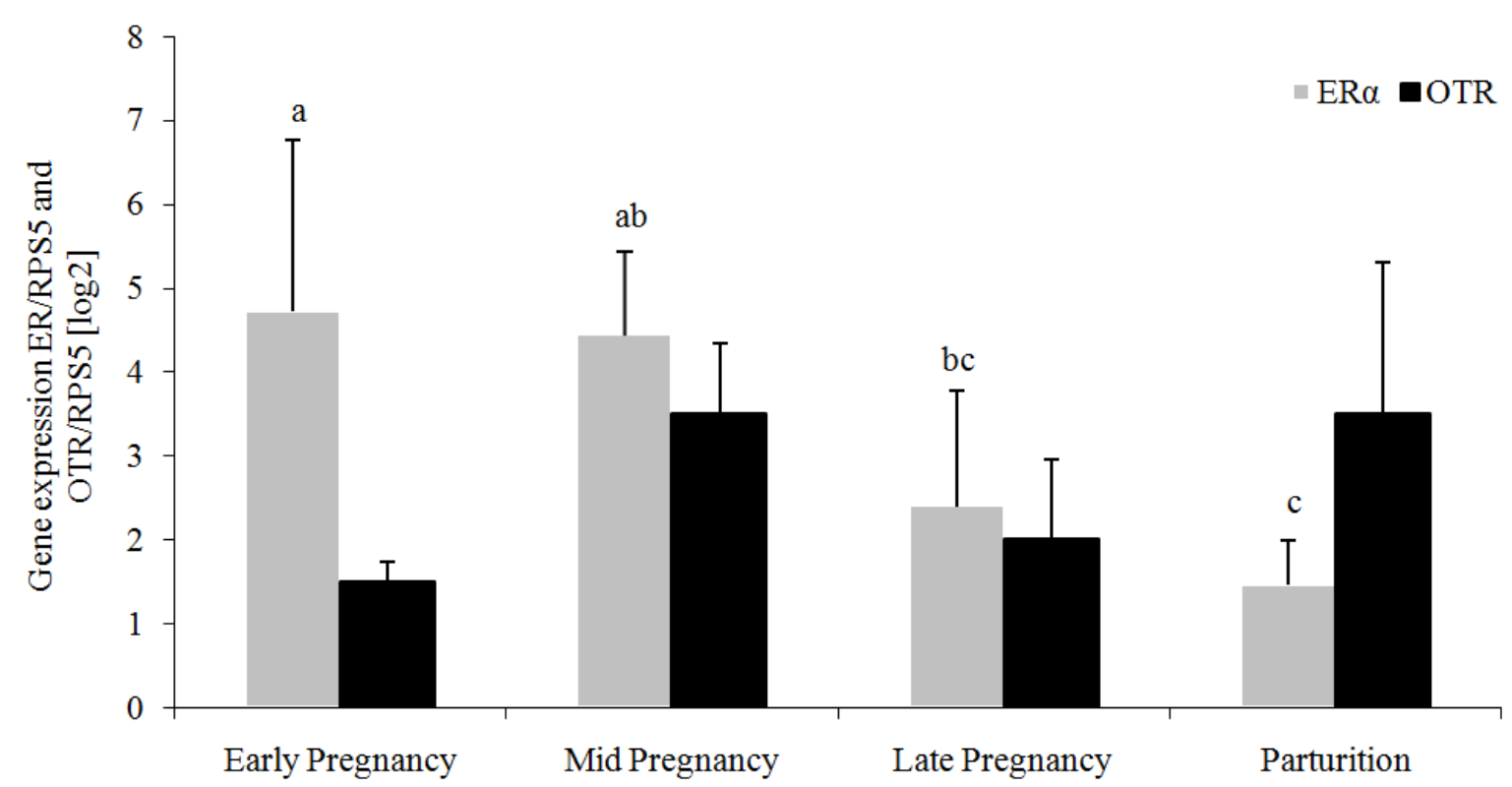

Fig. 1. ER $\alpha$ mRNA and OTR mRNA relative expression in placenta during Early, Mid and Late Pregnancy and Parturition in dogs. a,b,c values with different superscript letters differ significantly $(\mathrm{p}<0.05)$

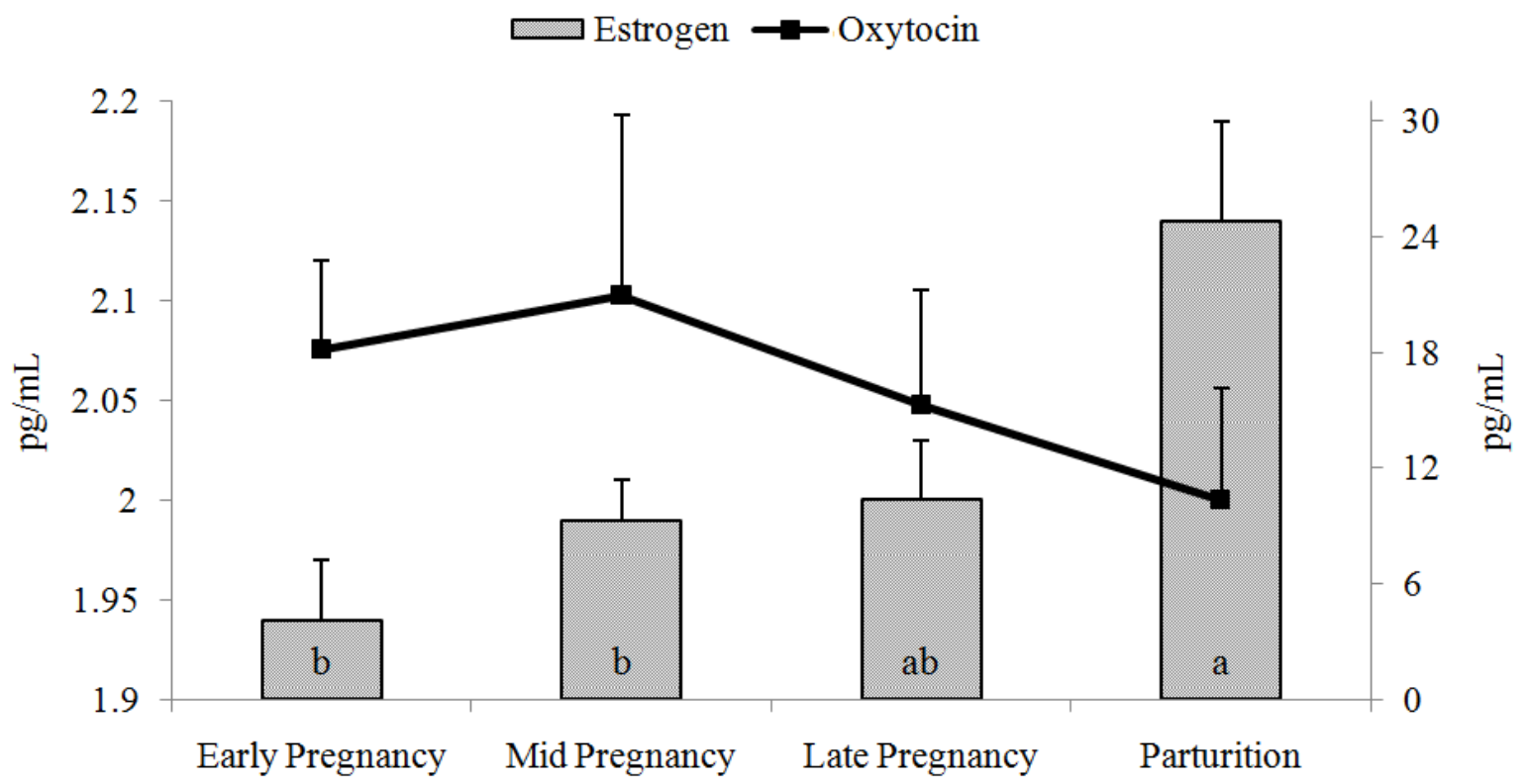

Fig. 2. Serum estrogen and oxytocin concentrations during Early, Mid and Late Pregnancy and Parturition in dogs. ${ }^{a, b}$ values with different superscript letters differ significantly for estrogen concentration among groups $(\mathrm{p}<0.05)$

\section{Correlation Analysis}

Regardless of the stage of pregnancy or parturition, placental ER $\alpha$ mRNA positively correlated with OTR mRNA $\quad(\mathrm{r}=0.94, \mathrm{p}<0.0001)$. During late pregnancy, a positive correlation $(\mathrm{r}=0.73, \mathrm{p}=0.04)$ was observed between placental ER $\alpha$ mRA and oxytocin serum concentration.

\section{Discussion}

The present work aimed to follow-up the placenta tissue expression of ER $\alpha$ and OTR mRNA in a temporal manner and to establish a relationship with the estrogen and oxytocin concentrations in the periparturient bitch.

The results of the current experiment reveal a progressive decrease in ER $\alpha$ mRNA expression in the 
canine placenta tissue along gestation. Although we do not have data of the expression on the protein level, these findings suggest a higher responsiveness to estrogen during early pregnancy (up to 20 days), around the time embryonic implantation and placental development begins in dogs. In many mammalian species, estrogen is synthesized by the placenta and it is autocrinally responsible for placental growth and differentiation (Schuler et al., 2002). Therefore, we can speculate that estrogen plays also a role in the development and growth of the canine placenta, in a more likely endocrine manner. In fact, estrogen is recognized to be involved in cell division and hypertrophy, as well as in placental vascular development (Tamada and Ichikawa, 1980). In dogs, Vermeirsch et al. (2000) observed immunohistochemical staining for $E R \alpha$ solely in the mesenchimal decidua cells, surrounding endothelial cells, between the maternal and fetal components of the placenta and at the hypertrophied basement membrane of the maternal capillaries of the placental labyrinth. Moreover, estrogen receptors and ER mRNAs are present in the cells surrounding the myometrial blood vessels of ewes, indicating that estrogen is involved in blood flow during pregnancy (Wu et al., 1996). Furthermore, estrogen participates in the conceptus morphological changes, such as fetal elongation and acquisition of a cylindrical form in rats (Tamada and Ichikawa, 1980). In light of our results and others statements, we can hypothesize that the influence of estrogen on the canine placenta tissue is focused in a more hemodynamic and morphological action, particularly during the initial phases of fetal and placental development. Conversely, after 40 days of gestation until whelping, we observed a decreased expression of ER $\alpha$ mRNA in the placenta tissue, suggesting a less expressive influence of estrogen on placental activity and fetal development at this time point. Thus, we can infer that the canine placenta tissue responds to estrogenic stimuli in a temporal manner.

Interestingly, the expression of ER $\alpha$ mRA in the canine placenta tissue positively correlated with the circulating concentrations of oxytocin exclusively in the Late Pregnancy Group. This data can allude to a causeeffect relation, i.e., changes in oxytocin concentrations at the end of gestation can alter the placenta responsiveness to estrogen. In other words, oxytocin can sensitize the placenta for estrogen stimulation only at final gestation, allowing for an exogenous interference to promote changes such as estrogen-induced vascular development. As a hint, we suggest that the administration of oxytocin in the bitch near term can have a beneficial effect in placental blood flow and oxygenation. In humans, plasma OT concentrations remain low throughout the pregnancy and birth. However, estradiol treatment results in increased circulating oxytocin levels (Mitchell et al., 1998;
Amico et al., 1981). Klarenbeek et al. (2007) demonstrated in dogs that OT concentrations remain low at the end of pregnancy, increasing only during the expulsion stage of vaginal labor. Our results are consistent with the work of Klarenbeek et al. (2007), because the OT levels remained constant throughout the pregnancy and first stage of labor. These observations suggest that circulating OT in dogs minimally affects the induction of labor. Therefore, the activation of myometrial OT receptors may occur downstream of the paracrine activity of placental OT, rather than as an endocrine manner.

Regarding the endocrinology of late gestation and parturition, we observed a singular feature in dogs. While the increasing concentration of estrogen stimulates the rise in uterine oxytocin receptors towards the initiation of labor in women and other animal species (Blanks et al., 2003; Spencer et al., 2004), we could not find a correlation between estrogen concentration and the expression of placental OTR mRNA. The placenta is considered to be one of the OT-synthesizing organs responsible for stimulating endometrial PGF2 $\alpha$ production, resulting in luteolysis at the beginning of labor (Iliodromiti et al., 2012). In dogs, we could not show a link among estrogen concentration, the increase in placental oxytocin receptors at term pregnancy and the initiating of labor. On the other hand, we showed a positive correlation between the OTR and ER $\alpha$ mRNA expressions in the placenta. Therefore, we should consider a possible stimulation mechanism that acts both on the expression of OTR and ER $\alpha$ mRNA in the canine placenta tissue. For this, studies should be conducted to verify the direct influence of the signaling by the fetal HypothalamicPituitary-Adrenal (HPA) axis and the role of placental Corticotrophin Releasing Hormone $(\mathrm{CRH})$ in the stimulation of oxytocin and prostaglandin synthesis by the canine placenta. Further studies on OTR sensitization should be performed in order to determine the total number of binding sites when exposed to endogenous oxytocin, as to consider a possible change in the binding affinity to oxytocin towards parturition. Moreover, the possibility that progesterone down regulates OTR mRNA should be further investigated using experiments on the hormonal control of pregnancy.

To our knowledge, there are few studies that demonstrate the simultaneous activity of estrogen and oxytocin in the placenta during pregnancy and parturition in dogs. Hence, this is the first research to show both the endocrine profile of estrogen and oxytocin and the hormonal receptors in the canine placenta throughout pregnancy. Although we haven't obtained results on the estrogen and oxytocin expression at the protein level yet, our results highlight the possible application of a hormonal treatment in the periparturient bitch, with a focus on placenta as the target tissue. 


\section{Conclusion}

As a descriptive study, we conclude that Estrogen Receptor (ER) mRNA in the canine placental tissue varies in a time-dependent manner. Placenta tissue ER $\alpha$ mRNA expression showed a progressive decrease along gestation towards parturition, while OTR mRNA expression remained unchanged. In addition, circulating levels of oxytocin positively correlate with placental ER $\alpha$ mRNA expression.

\section{Author's Contributions}

Gisele Almeida Lima Veiga and Camila Infantosi Vannucch: Conceptualized and supervised the research, collected samples, drafted the manuscript, ran all statistical tests and have read and approved the manuscript.

Marcella Pecora Milazzotto: Conceptualized and supervised the research and have read and approved the manuscript.

Marcilio Nichi: Ran all statistical tests and have read and approved the manuscript.

Cristina de Fatima Lucio and Liege Cristina Garcia Silv: Collected samples and have read and approved the manuscript.

\section{Conflict of Interest}

The researchers have no conflict of interest.

\section{References}

Amico, J.A., S.M. Seif and A.G. Robinson, 1981. Oxytocin in human plasma: Correlation with neurophysin and stimulation with estrogen. J. Clin. Endocrinol. Metabolism, 52: 988-993.

DOI: $10.1210 /$ jcem-52-5-988

Blanks, A.M., M. Vatish, M.J. Allen, G. Ladds and N.C.de Wit et al., 2003. Paracrine oxytocin and estradiol demonstrate a spatial increase in human intrauterine tissues with labor. J. Clin. Endocrinol. Metabolism, 88: 3392-3400.

DOI: $10.1210 /$ jc. 2002-021212

Chan, W.Y., D.L. Chen and M. Manning, 1993. Oxytocin receptor subtypes in the pregnant rat myometrium and decidua: Pharmacological differentiations. Endocrinology, 132: 1381-1386. DOI: $10.1210 /$ endo.132.3.8382600

Chibbar, R., F.D. Miller and B.F. Mitchell, 1993. Synthesis of oxytocin in amnion, chorion and decidua may influence the timing of human parturition. J. Clin. Investigat., 91: 185-192. DOI: 10.1172/JCI1 16169

Concannon, P.W., 2009. Endocrinologic control of normal canine ovarian function. Reproduct. Domestic Anim., 44: 3-15.

DOI: $10.1111 / \mathrm{j} .1439-0531.2009 .01414 . x$
Elias, L.L., J. Antunes-Rodrigues, P.C. Elias and A.C. Moreira, 1997. Effect of plasma osmolality on pituitary-adrenal responses to corticotropinreleasing hormone and atrial natriuretic peptide changes in central diabetes insipidus. J. Clin. Endocrinol. Metabolism, 82: 1243-1247.

DOI: $10.1210 /$ jcem.82.4.3884

Evans, H.E. and W.O. Sack, 1973. Prenatal development of domestic and laboratory mammals: Growth curves, external features and selected references. Anatomia, Histologia, Embryol., 2: 11-45. DOI: $10.1111 / \mathrm{j} .1439-0264.1973 . t b 00253 . x$

Fuchs, A.R., S. Periyasamy, M. Alexandrova and M.S. Soloff, 1983. Correlation between oxytocin receptor concentration and responsiveness to oxytocin in pregnant rat myometrium: Effects of ovarian steroids. Endocrinology, 113: 742-749.

DOI: 10.1210/endo-113-2-742

Gram, A., A. Boos and M.P. Kowalewski, 2014. Uterine and placental expression of canine oxytocin receptor during pregnancy and normal and induced parturition. Reproduct. Domestic Anim., 49: 41-49. DOI: $10.1111 /$ rda. 12295

Hoffmann, B., R. Hoveler, B. Nohr and S.H. Hasan, 1994. Investigations on hormonal changes around parturition in the $\operatorname{dog}$ and the occurrence of pregnancy-specific non conjugated oestrogens. Experim. Clin. Endocrinol., 102: 185-189.

DOI: $10.1055 / \mathrm{s}-0029-1211280$

Iliodromiti, Z., N. Antonakopoulos, S. Sifakis, P. Tsikouras and A. Daniilidis et al., 2012. Endocrine, paracrine and autocrine placental mediators in labor. Hormones, 11: 397-409.

DOI: $10.14310 /$ horm.2002.1371

Klarenbeek, M., A.C. Okkens, H.S. Kooistra, J.A. Mol and M.M. Bevers et al., 2007. Plasma oxytocin concentrations during late pregnancy and parturition in the dog. Theriogenology, 68: 1169-1176. DOI: $10.1016 /$ j.theriogenology.2007.08.017

Klonisch, T., S. Hombach-Klonisch, C. Froehlich, J. Kauffold and K. Steger et al., 1999. Canine preprorelaxin: Nucleic acid sequence and localization within the canine placenta. Biol. Reproduct., 60: 551-557. DOI: 10.1095/biolreprod60.3.551

Kowalewski, M.P., H.B. Beceriklisoy, C. Pfarrer, S. Aslan and H. Kindahl et al., 2010. Canine placenta: A source of prepartal prostaglandins during normal and antiprogestin-induced parturition. Reproduction, 139: 655-664. DOI: 10.1530/REP-09-0140

Larcher, A., J. Neculcea, C. Breton, A. Arslan and F. Rozen et al., 1995. Oxytocin receptor gene expression in the rat uterus during pregnancy and the estrous cycle and in response to gonadal steroid treatment. Endocrinology, 136: 5350-5356.

DOI: $10.1210 /$ endo.136.12.7588281 
Mitchell, B.F., X. Fang and S. Wong, 1998. Oxytocin: A paracrine hormone in the regulation of parturition? Rev. Reproduct., 3: 113-122. DOI: $10.1530 /$ ror. 0.0030113

Nishiyama, T., S. Tsumagari, M. Ito, J. Kimura and G. Watanabe et al., 1999. Immunohistochemical study of steroidogenic enzymes in the ovary and placenta during pregnancy in the dog. Anatomia Histologia Embryol., 28: 125-129. DOI: 10.1046/j.1439-0264.1999.00170.x

Pfaffl, M.W., G.W. Horgan and L. Dempfle, 2002. Relative expression software tool (RESTC) for group-wise comparison and statistical analysis of relative expression results in real-time PCR. Nucleic Acids Res., 30: e36- e36. DOI: 10.1093/nar/30.9.e36

Schuler, G., C. Wirth, U. Teichmann, K. Failing and R. Leiser et al., 2002. Occurrence of estrogen receptor $\alpha$ in bovine placentomes throughout mid and late gestation and at parturition. Biol. Reproduct., 66: 976-982. DOI: 10.1095/biolreprod66.4.976

Spencer, T.E., G.A. Johnson, R.C. Burghardt and F.W. Bazer, 2004. Progesterone and placental hormone actions on the uterus: Insights from domestic animals. Biol. Reproduct., 71: 2-10. DOI: 10.1095/biolreprod.103.024133

Tamada, H., N. Kawate, N. Kawata, T. Inaba and K. Kida et al., 2010. Detection of relaxin mRNA in the corpus luteum, uterus and uterine cervix in the bitch. J. Vet. Med. Sci., 72: 1383-1386.

DOI: $10.1292 /$ jvms.09-0485
Tamada, H. and S. Ichikawa, 1980. The effect of estrogen on fetal survival in progesterone-treated ovariectomized rats. Endocrinol. Japonica, 27: 163-167. DOI: 10.1507/endocrj1954.27.163

Veiga, G.A., M.P. Milazzotto, C.F. Lúcio, L.C. Silva and C.I. Vannucchi, 2014. Estrogen and oxytocin receptors in the canine corpusluteum during pregnancy and parturition. Brazilian J. Vet. Res. Anim. Sci., 51: 346-351.

DOI: $10.11606 /$ issn.1678-4456.v51i4p346-351

Veiga, G.A., M.P. Milazzotto, M. Nichi, C.F. Lúcio and L.C. Silva et al., 2015. Gene expression of estrogen and oxytocin receptors in the uterus of pregnant and parturient bitches. Brazilian J. Med. Biol. Res., 48: 339-343. DOI: 10.1590/1414-431X20143969

Vermeirsch, H., P. Simoens and H. Lauwers, 2000. Immunohistochemical detection of the estrogen receptor-alpha and progesterone receptor in the canine pregnant uterus and placental labyrinth. Anatomical Record, 260: 42-50. PMID: 10967535

Wu, W.X., J.B. Derks and P.W. Nathanielsz, 1996. Effects of glucocorticoids on estrogen receptor messenger ribonucleic acid in the pregnant ovine myometrium in vivo and in vitro. Biol. Reproduct., 54: 230-241. DOI: 10.1095/biolreprod54.1.230 